\title{
Relationship between Lipoprotein(a), Metabolic Syndrome, and Carotid Atherosclerosis in Older Japanese People
}

\author{
Kazuhiko Kotani $^{a, b}$ Hisashi Shimohiro $^{c}$ Seiji Adachi $^{d}$ Naoki Sakane $^{b}$ \\ a Division of Health Administration and Promotion, Faculty of Medicine, Tottori University, Yonago, \\ ${ }^{b}$ Department of Preventive Medicine, Clinical Research Institute for Endocrine and Metabolic Disease, \\ National Hospital Organization Kyoto Medical Center, Kyoto, ' Division of Clinical Laboratory, \\ Tottori University Hospital, Yonago, and ${ }^{\mathrm{d}}$ Division of General Internal Medicine and Community Medicine, \\ Fujii Masao Memorial Hospital, Kurayoshi, Japan
}

\author{
Key Words \\ Lipoprotein · Carotid intima-media thickness $\cdot$ Metabolic \\ disorder · Aging biology
}

\begin{abstract}
Background: Lipoprotein(a) [Lp(a)] or metabolic syndrome (MS) is individually considered an atherosclerotic factor. Serum $L p(a)$ may reportedly show the additive effects on atherosclerosis under certain particular pathologies. We do not know the association between serum Lp(a) and carotid artery intima-media thickness (CIMT) with relation to MS in older people. Objective: The present study aims at investigating the relationship between Lp(a) and CIMT levels in relation to MS among older subjects. Methods: We studied 182 Japanese subjects of $\geq 60$ years (mean 72.5 years), free of cardiovascular/cerebrovascular disease. MS was based on the NCEP-ATPIII criteria with a minor modification for Japanese. The CIMT was ultrasonographically measured. Results: The CIMT levels were significantly greater in the MS group $(\mathrm{n}=60,1.03 \pm 0.22 \mathrm{~mm})$ than the non-MS group $(\mathrm{n}=122$, $0.96 \pm 0.22 \mathrm{~mm}$ ). Multivariate analysis, using Lp(a) levels or the product term for interaction between $L p(a)$ and MS, showed that age significantly and independently correlated to CIMT, along with male gender. Discussion: Even when
\end{abstract}

Lp(a) and MS were simultaneously considered, age was the best determinant of CIMT in this population. The mechanism of our results including weak additive effects of $L p(a)$ and $M S$ among older subjects may be partly throughout aging.

Copyright $\odot 2008$ S. Karger AG, Basel

\section{Introduction}

Lipoprotein(a) [Lp(a)], a macromolecule consisting of a particle of low-density lipoprotein (LDL) linked to apolipoprotein(a), is highly homologous with plasminogen, so the characteristics may contribute to the processes of atherothrombosis. The plasma/serum Lp(a) level is considered an independent risk factor for atherosclerotic events such as cardiovascular and cerebrovascular disease [1], while conflicting data exists [2, 3]. Positive associations between $\mathrm{Lp}(\mathrm{a})$ and carotid artery intima-media thickness (CIMT), a well-established surrogate index of coronary/cerebral atherosclerosis, have reported in some $[4,5]$ but not all [6-8] studies.

Similarly, metabolic syndrome (MS) has recently become considered a risk factor for atherosclerosis and its sequelae such as cardiovascular and cerebrovascular disease $[9,10]$, and on the other hand, there have been more

\section{KARGER}

Fax +4161306 1234

E-Mail karger@karger.ch

www.karger.com
(C) 2008 S. Karger AG, Basel

0304-324X/08/0546-0361\$24.50/0

Accessible online at:

www.karger.com/ger
Kazuhiko Kotani, MD, PhD

Division of Health Administration and Promotion

Faculty of Medicine, Tottori University

86 Nishi-cho, Yonago 683-8503 (Japan)

Tel. +81 85938 6113, Fax +81 85938 6110, E-Mail kakotani@grape.med.tottori-u.ac.jp 
recent proposals on non-significance of MS on cardiovascular and cerebrovascular mortality $[11,12]$. As well, MS has been shown as a determinant of increased CIMT [13], while there is a report that CIMT is not associated with insulin resistance, which underlies MS [14]. Information about the associations between MS and atherosclerosis in various populations and conditions is eagerly waited for.

Notably, Lp(a) might promote atherosclerosis under the presence of other atherogenic pathologies and conditions. This has been reported in patients with diabetes [4, 15], severe hypercholesterolemia [16], peritoneal dialysis [17], and smoking [4]. Nevertheless, no information is available on whether the atherogenic effects of $L p(a)$ are enhanced by an interaction with MS. These topics are crucial especially in older people, because of their high prevalence of atherosclerotic disease. Accordingly, the aim of the present study was to examine the relationship between Lp(a) and CIMT levels in relation to MS, with a restriction to older subjects.

\section{Subjects and Methods}

A cross-sectional analysis of serum Lp(a) and CIMT levels was conducted among 182 community-dwelling Japanese subjects of $\geq 60$ years old ( 62 men and 120 women with a mean age of 72.5 \pm 7.3 [standard deviation (SD)] years) free of manifest cardiovascular and cerebrovascular disease and not on medications which affect blood pressure (BP), blood glucose and lipoprotein. There were no subjects who were on hormone replacement treatment and alcohol abusers/heavy drinkers. 122 subjects without MS (men:women $=40: 82$; age $73.2 \pm 7.6$ years) and 60 with MS (men:women $=22: 38$; age $71.0 \pm 6.6$ years) were included. The study was approved by the institutional ethics committee and each subject gave informed consent.

In the data collection, current smoking was defined as a smoker. BP values were measured in the upper arm of seated patients using a standard sphygmomanometer. Overnight fasting plasma glucose and serum triglyceride values were enzymatically measured, as well as high-density lipoprotein (HDL) cholesterol and LDL cholesterol values were measured using the homogeneous methods. Lp(a) values were determined using the latex immunoassay method. Based on the NCEP-ATPIII report [18] with a minor modification of obesity for Japanese [13], MS was defined as the presence of at least three of the following five conditions: (1) obesity (identified by body mass index [BMI] of $\geq 25 \mathrm{~kg} / \mathrm{m}^{2}$ ), (2) elevated BP, (3) hypertriglyceridemia, (4) low HDL cholesterolemia, and (5) elevated glucose.

An ultrasonograph (SSD-900, Aloka Co., Ltd, Tokyo, Japan) with a $7.5-\mathrm{MHz}$ linear type B-mode probe was used to measure CIMT, as reported previously [19]. The intima-media thickness of the common carotid artery was bilaterally measured in segments free of plaque (plaque was defined as wall thickening of at least $\geq 50 \%$ compared to the adjacent thickness) with longitudinal and
Table 1. Clinical characteristics in the group with MS and without MS

\begin{tabular}{lcc}
\hline Variable & $\begin{array}{l}\text { Non-MS group } \\
(\mathrm{n}=122)\end{array}$ & $\begin{array}{l}\text { MS group } \\
(\mathrm{n}=60)\end{array}$ \\
\hline Age, years & $73.2 \pm 7.6$ & $71.0 \pm 6.6$ \\
Men/women & $40 / 82$ & $22 / 38$ \\
Smoking habit $^{\mathrm{a}}, \mathrm{n}(\%)$ & $6(4.9)$ & $6(10.0)$ \\
Body mass index, kg/m $^{2}$ & $21.3 \pm 2.7$ & $24.5 \pm 3.0^{* *}$ \\
Systolic blood pressure, mm Hg & $138.3 \pm 16.5$ & $147.0 \pm 14.1^{* *}$ \\
Diastolic blood pressure, mm Hg & $78.7 \pm 7.6$ & $80.4 \pm 7.7$ \\
Triglyceride, mmol/l & $1.11 \pm 0.57$ & $1.64 \pm 0.73^{* *}$ \\
HDL cholesterol, mmol/l & $1.53 \pm 0.40$ & $1.32 \pm 0.39^{* *}$ \\
Glucose, mmol/l & $5.60 \pm 1.06$ & $6.31 \pm 1.32^{* *}$ \\
LDL cholesterol, mmol/l & $3.07 \pm 0.74$ & $3.29 \pm 0.86$ \\
Lp(a), mmol/l & $0.60 \pm 0.46$ & $0.62 \pm 0.51$ \\
$\quad$ Median Lp(a), mmol/l & 0.54 & 0.49 \\
Lp(a) $\geq 0.78 \mathrm{mmol} / \mathrm{l}, \mathrm{n}(\%)$ & $27(22.1)$ & $14(23.3)$ \\
CIMT, mm & $0.96 \pm 0.22$ & $1.03 \pm 0.22^{*}$ \\
$\quad$ CIMT $\geq 1.0 \mathrm{~mm}, \mathrm{n}(\%)$ & $65(53.3)$ & $32(53.3)$
\end{tabular}

MS = Metabolic syndrome; HDL = high-density lipoprotein; $\mathrm{LDL}=$ low-density lipoprotein; $\mathrm{Lp}(\mathrm{a})=$ lipoprotein $(\mathrm{a})$; CIMT $=$ carotid artery intima-media thickness. Data are expressed as means $\pm \mathrm{SD}$.

${ }^{\text {a }}$ Smoking habit was defined as a current smoker. A statistical significance level (non-MS vs. MS group): ${ }^{*} \mathrm{p}<0.05,{ }^{* *} \mathrm{p}<0.01$.

transverse scans. After three measurements of CIMT were taken at the thickest site and at two other points $(10 \mathrm{~mm}$ upstream and $10 \mathrm{~mm}$ downstream from the thickest site), these averaged levels were used for analyses.

Values are given as mean $\pm \mathrm{SD}$. Mean levels or distribution tendencies between groups were compared using the unpaired t test or $\chi^{2}$ test. Age, BMI, smoking status, LDL cholesterol, the presence of MS and Lp(a) values as explanatory variables and carotid atherosclerosis (defined as CIMT of $\geq 1.0 \mathrm{~mm} \mathrm{[13])} \mathrm{as} \mathrm{a} \mathrm{cri-}$ terion variable were entered to a multivariate logistic regression model to estimate odds ratios after adjustment for confounders. $\mathrm{Lp}$ (a) levels of $\geq 0.78 \mathrm{mmol} / \mathrm{l}$ have been considered the threshold to an elevated atherosclerotic disease risk [8], so the presence of $\mathrm{Lp}(\mathrm{a})$ of $\geq 0.78 \mathrm{mmol} / \mathrm{l}$ was also substituted for $\mathrm{Lp}$ (a) values themselves in the same analysis. Subsequently, product term in Lp(a) and MS was used to assess interactions (effect modification) between them in the logistic models. $\mathrm{p}<0.05$ was considered significant.

\section{Results}

The studied subjects' clinical characteristics are shown in table 1 . The mean $\mathrm{Lp}(\mathrm{a})$ level of all subjects was $0.61 \pm$ $0.48 \mathrm{mmol} / \mathrm{l}$. There were no differences in the median 
Table 2. Logistic regression analysis for carotid atherosclerosis using the variable of crude $\operatorname{Lp}(\mathrm{a})$ values or $\operatorname{Lp}(\mathrm{a}) \geq 0.78 \mathrm{mmol} / \mathrm{l}$, controlled for possible risk factors

\begin{tabular}{|c|c|c|}
\hline Covariates & $\begin{array}{l}\text { Odds ratios } \\
(95 \% \mathrm{CI})\end{array}$ & $\mathrm{p}$ value \\
\hline \multicolumn{3}{|c|}{ Model 1: using the variable of crude Lp(a) values } \\
\hline Age & $1.10(1.05-1.16)$ & $<0.0001^{* *}$ \\
\hline Male gender ${ }^{\mathrm{a}}$ & $2.24(1.05-4.81)$ & $0.038^{*}$ \\
\hline Smoking habit ${ }^{\mathrm{b}}$ & $1.44(0.32-6.83)$ & 0.613 \\
\hline LDL cholesterol & $1.01(0.99-1.02)$ & 0.305 \\
\hline $\mathrm{MS}^{\mathrm{b}}$ & $1.19(0.61-2.34)$ & 0.607 \\
\hline $\operatorname{Lp}(\mathrm{a})$ & $1.00(0.98-1.01)$ & 0.705 \\
\hline \multicolumn{3}{|c|}{ Analysis for interaction between MS and crude Lp(a) } \\
\hline Age & $1.10(1.05-1.15)$ & $<0.0001^{*}$ \\
\hline Male gender ${ }^{\mathrm{a}}$ & 2.23 & $0.039^{*}$ \\
\hline Smoking habit ${ }^{\mathrm{b}}$ & 1.35 & 0.701 \\
\hline LDL ch & ) & 0 \\
\hline$M S^{b} \times L p(a)$ & $.99-1.03)$ & 0.535 \\
\hline \multicolumn{3}{|c|}{ Model 2: using the variable of $L p(a) \geq 0.78 \mathrm{mmol} / \mathrm{l}$} \\
\hline Age & $1.10(1.05-1.16)$ & $<0.0001^{* *}$ \\
\hline Male gender ${ }^{\mathrm{a}}$ & 2.3 & $0.029^{*}$ \\
\hline Smoking habit ${ }^{\mathrm{b}}$ & 1.18 & 0.836 \\
\hline LDL cholesterol & $1.00(0.99-1.02)$ & 0.429 \\
\hline $\mathrm{MS}^{\mathrm{b}}$ & $1.21(0.62-2.39)$ & 0.576 \\
\hline $\mathrm{Lp}(\mathrm{a}) \geq 0.78 \mathrm{mmol} / \mathrm{l}^{\mathrm{b}}$ & $1.64(0.75-3.56)$ & 0.213 \\
\hline \multicolumn{3}{|c|}{ Analysis for interaction between MS and Lp(a) $\geq 0.78 \mathrm{mmol} / \mathrm{l}$} \\
\hline Age & $1.10(1.05-1.16)$ & $<0.0001^{*}$ \\
\hline Male gender ${ }^{\mathrm{a}}$ & $2.17(1.02-4.66)$ & $0.046^{*}$ \\
\hline Smoking habit ${ }^{\mathrm{b}}$ & $1.18(0.25-5.55)$ & 0.832 \\
\hline LDL cholesterol & $1.00(0.99-1.02)$ & 0.494 \\
\hline $\mathrm{MS}^{\mathrm{b}} \times \mathrm{Lp}(\mathrm{a}) \geq 0.78 \mathrm{mmol} / \mathrm{l}^{\mathrm{b}}$ & $3.02(0.75-12.19)$ & 0.121 \\
\hline
\end{tabular}

Data show the results of multivariate logistic regression analysis. Carotid atherosclerosis is defined as carotid artery intimamedia thickness of $\geq 1.0 \mathrm{~mm}$. CI = Confidence interval; LDL = low-density lipoprotein; MS = metabolic syndrome.

${ }^{a}$ Female: 0 , male: $1{ }^{b}$ absence: 0 , presence: 1 . Age (per 1 year), LDL cholesterol (per $0.26 \mathrm{mmol} / \mathrm{l}$ ), Lp(a) (per $0.26 \mathrm{mmol} / \mathrm{l}$ in Model 1): continuous variable.

A statistical significance level: ${ }^{*} \mathrm{p}<0.05,{ }^{* *} \mathrm{p}<0.01$.

and mean $\mathrm{Lp}(\mathrm{a})$ levels as well as frequency distributions of $\mathrm{Lp}(\mathrm{a})$ of $\geq 0.78 \mathrm{mmol} / \mathrm{l}$ between groups with versus without MS, respectively. The mean CIMT level of all subjects was $0.97 \pm 0.22 \mathrm{~mm}$, and the levels were slightly but significantly higher in the group with MS than that without MS. The prevalence of carotid atherosclerosis, defined by CIMT levels of $\geq 1.0 \mathrm{~mm}$, was similar between groups with and without MS.

Logistic regression analysis using crude $\mathrm{Lp}(\mathrm{a})$ values demonstrated age to be significantly associated with
CIMT, along with male gender (table 2: model 1). When the product term for interaction between $L p(a)$ values and MS was used, we did not detect the effect modification by the interaction. Logistic analysis using the presence of $\mathrm{Lp}(\mathrm{a})$ of $\geq 0.78 \mathrm{mmol} / \mathrm{l}$ demonstrated age and male gender to be significantly associated with CIMT (table 2: model 2). When the product term for interaction between $\mathrm{Lp}(\mathrm{a})$ of $\geq 0.78 \mathrm{mmol} / \mathrm{l}$ and MS was used, the term seemed to have more enhanced effects on CIMT than a sole variable, but the effect modification remained insignificant.

\section{Discussion}

In our study, it was unlikely that both Lp(a) levels and MS showed remarkable interactions on CIMT, even if both $\mathrm{Lp}(\mathrm{a})$ and MS are considered atherosclerotic risk factors. In this situation, age was identified as the strongest contributor to CIMT, and male gender ranked second. Our study results might expand the fact that age is one of the strongest independent risk factors of carotid atherosclerosis [20] even in the aged population. Moreover, an association between CIMT and male gender was thought to agree with previous findings of a greater CIMT in men than women $[6,14]$.

In our simple tests, the presence of MS was associated with a higher CIMT level (which was likely consistent to earlier reports [13]), and $\mathrm{Lp}(\mathrm{a})$ was not associated with CIMT (which likely supported earlier reports [6-8]). Subsequently, however, multivariate analyses could not confirm any independent association between CIMT and both $\mathrm{Lp}(\mathrm{a})$ and MS alone, in addition to no clear effect modification by interaction of $\mathrm{Lp}(\mathrm{a})$ and MS on CIMT (this effect modification is a primary focus in our study). Although the detailed mechanism on more influence of age, than Lp(a) and MS, on CIMT remains unclear, Lp(a) and other major atherosclerotic risk factors have been suggested to be less powerful in predicting atherosclerotic risk throughout aging [6]. Furthermore, among earlier reports examining the relationship between MS and atherosclerotic disease [9-12], no associations are observed particularly in rural Japanese populations, consisting of older subjects $[11,12]$ : these report results may have some concern with the present study results. Additionally, other reasons for the inconsistency in the association between studies including ours might be differences in the study design and population. Our study including no subjects with any vascular events and medications (maybe recruiting the subjects with relative- 
ly moderate degree of pathophysiology of MS, i.e. hypertension) can induce diminished effects on CIMT (this is given care when generalizing the results).

This study also had potential limitations such as a cross-sectional design and relatively small sample size. Although insignificant in our study population, the possibility that the interaction between high Lp(a) status (the levels of $\geq 0.78 \mathrm{mmol} / \mathrm{l}$ ) and MS had some enhanced effects on CIMT should be reconsidered as a future issue of sample collection. Further studies with a prospective design and larger sample size are required.

In summary, our study has disclosed that age is the best determinant of CIMT, even when both Lp(a) and MS are considered atherosclerotic risk factors, in older Japanese people. High Lp(a) levels and MS had additive but insignificant effects on CIMT in this population. The mechanism of our results may partly be throughout aging. Deeper understanding of vascular biology on aging and anti-aging strategy will be a future important challenge. Our theory calls for more studies.

\section{Acknowledgement}

This study was supported in part by a Grant-in-Aid from the Foundation for the Development of the Community, Japan.

\section{References}

1 Ariyo AA, Thach C, Tracy R: Lp(a) lipoprotein, vascular disease, and mortality in the elderly. N Engl J Med 2003;349:2108-2115.

$\checkmark 2$ Ridker PM, Hennekens H, Stampfer MJ: A prospective study of lipoprotein(a) and the risk of myocardial infarction. JAMA 1993; 270:2195-2199.

3 Alfthan G, Pekkanen J, Jaluhiainen M, Pitkäniemi J, Karvonen M, Tuomilehto J, Salonen JT, Ehnholm C: Relation of serum homocysteine and lipoprotein(a) concentrations to atherosclerotic disease in a prospective Finnish population based study. Atherosclerosis 1994;106:9-19.

-4 Schreiner PJ, Heiss G, Tyroler HA, Morrisett JD, Davis CE, Smith R: Race and gender differences in the association of $\mathrm{Lp}(\mathrm{a})$ with carotid artery wall thickness. The Atherosclerosis Risk in Communities (ARIC) Study. Arterioscler Thromb Vasc Biol 1996;16:471478.

5 Rossl A, Baldo-Enzi G, Ganzaroli C, Coscetti G, Calabro A, Baiocchi MR, Maiolino G, Pessina AC, Rossi GP: Relationship of early carotid artery disease with lipoprotein(a), apolipoprotein B, and fibrinogen in asymptomatic essential hypertensive patients and normotensive subjects. J Investig Med 2001; 4:505-513.

6 Denti L, Marchini L, Pasolini G, Baffoni MT, Ablondi F, Valenti G: Lp(a) and cerebrovascular disease in the elderly: correlations with the severity of extracranial carotid atherosclerosis assessed by ultrasonography. Acta Biomed Ateneo Parmense 1995;66:175-183.
-7 Sramek A, Reiber JH, Baak-Pablo R, Sturk A, Rosendaal FR: Lipoprotein(a) and ultrasonographically determined early atherosclerotic changes in the carotid and femoral artery. J Thromb Haemost 2003;1:374-379.

$\checkmark 8$ Grebe MT, Schoene E, Schaefer CA, Boedeker RH, Kemkes-Matthes B, Voss R, Tillmanns HH: Elevated lipoprotein(a) does not promote early atherosclerotic changes of the carotid arteries in young, healthy adults. Atherosclerosis 2006;190:194-198.

-9 Galassi A, Reynolds K, He J: Metabolic syndrome and risk of cardiovascular disease: a meta-analysis. Am J Med 2006;119:812-819.

10 Iso H, Sato S, Kitamura A, Imano H, Kiyama M, Yamagishi K, Cui R, Tanigawa T, Shimamoto T: Metabolic syndrome and the risk of ischemic heart disease and stroke among Japanese men and women. Stroke 2007;38: 1744-1751.

11 Niwa Y, Ishikawa S, Gotoh T, Kayaba K, Nakamura Y, Kajii E: Metabolic syndrome mortality in a population-based cohort study: Jichi Medical School (JMS) Cohort Study. J Epidemiol 2007;17:203-209.

12 Saito I, Konishi M, Watanabe K, Kondo H, Fujimoto K, Okada K: The metabolic syndrome and risk of stroke in a rural community in Japan (in Japanese/English abstract). Nippon Koshu Eisei Zasshi 2007;54:677683.

13 Kawamoto R, Tomita H, Oka Y, Ohtsuka N, Kamitani A: Metabolic syndrome and carotid atherosclerosis: role of elevated blood pressure. J Atheroscler Thromb 2005;12: 268-275.

- 14 Snehalatha C, Vijay V, Suresh Mohan R, Satyavani K, Sivasankari S, Megha T, Radhika S, Ramachandran A: Lack of association of insulin resistance and carotid intimal medial thickness in non-diabetic Asian Indian subjects. Diabetes Metab Res Rev 2001;17: 444-447.
15 Yamamoto M, Egusa G, Yamakido M: Carotidatherosclerosisandserumlipoprotein(a) concentrations in patients with NIDDM. Diabetes Care 1997;20:829-831.

16 Baldassarre D, Tremoli E, Franceschini G, Michelagnoli S, Sirtori CR: Plasma lipoprotein(a) is an independent factor associated with carotid wall thickening in severely but not moderately hypercholesterolemic patients. Stroke 1996;27:1044-1049.

- 17 Ohkuma T, Minagawa T, Takada N, Ohno M, Oda $\mathrm{H}$, Ohashi $\mathrm{H}$ : C-reactive protein, lipoprotein(a), homocysteine, and male sex contribute to carotid atherosclerosis in peritoneal dialysis patients. Am J Kidney Dis 2003;42:355-361.

18 Expert Panel on Detection, Evaluation, and Treatment of High Blood Cholesterol in Adults: Executive Summary of The Third Report of The National Cholesterol Education Program (NCEP) Expert Panel on Detection, Evaluation, and Treatment of High Blood Cholesterol in Adults (Adult Treatment Panel III). JAMA 2001;285:24862497.

19 Kawamori R, Yamasaki Y, Matsushima H, Nishizawa H, Nao K, Hougaku H, Maeda H, Handa N, Matsumoto M, Kamada T: Prevalence of carotid atherosclerosis in diabetic patients: ultrasound high-resolution B-mode imaging on carotid arteries. Diabetes Care 1992;25:1290-1294.

20 Gariepy J, Salomon J, Denarie N, Laskri F, Megnien JL, Levenson J, Simon A: Sex and topographic differences in associations between large-artery wall thickness and coronary risk profile in a French working cohort. The AXA Study. Arterioscler Thromb Vasc Biol 1998;18:584-590. 